doi: 10.2306/scienceasia1513-1874.2013.39.486

\title{
Expression and inhibition of MBD2 in gastric cancer
}

\author{
Miao He ${ }^{\mathrm{a}}$, Jing Fan ${ }^{\mathrm{b}}$, Rong Jiang ${ }^{\mathrm{c}}$, Wei-Xue Tang ${ }^{\mathrm{d}}$, Zi-Wei Wang ${ }^{\mathrm{a}, *}$ \\ a Department of General Surgery, First Affiliated Hospital of Chongqing Medical University, Chongqing, \\ 400016, China \\ b Department of Emergency, First Affiliated Hospital of Chongqing Medical University, Chongqing, 400016, \\ China \\ ${ }^{c}$ Laboratory of Stem Cell and Tissue Engineering, Institute of Basic Medicine, \\ Chongqing Medical University, Chongqing, 400016, China \\ d Laboratory Research Centre, First Affiliated Hospital of Chongqing Medical University, Chongqing, \\ 400016, China \\ *Corresponding author, e-mail: wangziwei571@163.com
}

Received 25 Sep 2012

Accepted 29 May 2013

\begin{abstract}
As gastric cancer (GC) involves changes in gene expression, proteins that bind to methylated DNA, such as methyl-CpG-binding domain protein 2 (MBD2) may be a potential target for cancer treatment. We used immunohistochemistry and immunofluorescence to detect the MBD2 expression in GC tissues and SGC-7901 (GC cell line), RT-PCR and western blotting to evaluate the knockdown of MBD2 by specific siRNAs, and MTT assay to analyse the proliferation of SGC-7901 after the MBD2-siRNA transfection. We found GC expression of MBD2 protein was higher than in matched non-cancerous tissues, and the MBD2 expression was associated with the size and histological grade of GC tissues. MBD2 protein was distributed in the nucleus of GC cells, and the MBD2 mRNA and protein could be inhibited by a specific siRNA. Finally, after $96 \mathrm{~h}$ of the MBD2-siRNA transfection, the growth rate of SGC-7901 decreased compared with controls. Hence MBD2 may be an underlying target of gastric cancer treatment.
\end{abstract}

KEYWORDS: methyl-CpG-binding domain protein 2, gastric neoplasm, RNA interference, siRNA

\section{INTRODUCTION}

DNA methylation is a major modification of eukaryotic genomes and plays an essential role in mammalian development. Human protein methyl-CpGbinding domain protein 2 (MBD2), a member of the methyl-CpG binding domain (MBD) family, is capable of binding specifically to methylated DNA and can repress transcription of methylated gene promoters. Hence MBD2 protein functions as a mediator of the biological consequences of DNA methylation signal. But interestingly, MBD2 is also reported to function as a demethylase to activate transcription, as DNA methylation causes gene silencing. In the field of malignant tumour research, MBD2 is found to play an important role in cancer progression ${ }^{1}$. In this study, we investigate the MBD2 expression in gastric cancer (GC) and the effect of MBD2 inhibition on GC cell proliferation. The result from this study should provide new insights into future epigenetic exploration on GC.

\section{MATERIALS AND METHODS}

\section{Ethics statement}

All experimental procedures were approved by the Ethics Committee of the First Affiliated Hospital of Chongqing Medical University.

\section{Clinical specimens}

Forty pairs of GC and matched non-cancerous tissue (located $>5 \mathrm{~cm}$ from cancerous areas) were all obtained from the Department of General Surgery of the First Affiliated Hospital of Chongqing Medical University. All tissues were fixed in formalin and embedded in paraffin for immunohistochemistry analysis, and the diagnosis was confirmed by pathological analysis.

\section{Immunohistochemistry}

The streptavidin-peroxidase (SP) method was adopted and performed. Primary antibody specific to MBD2 was purchased from Santa Cruz Biotechnology, USA. 
The SP Kit and DAB Kit were obtained from Beijing Zhongshan Company, China.

\section{Evaluation of staining}

MBD2 expressions in tissues were assessed by scoring the staining intensity and staining proportion. The staining intensity was recorded as negative $=0$, light $=1$, moderate $=2$, or strong $=3$. The staining proportion was recorded as $1(\leqslant 25 \%), 2(\leqslant 50 \%)$, $3(\leqslant 75 \%)$, or $4(>75 \%)$. The two values were multiplied for each slide to produce a terminal score. If the score was higher in GC than that in matched control, this pair of tissues was marked with a "+". The opposite condition was marked with a "-". If the scores were the same, the pair was marked with a " 0 ". Terminal scores of $0-3$ were defined as negative expression, 4-12 were defined as positive expression.

\section{Cell culture}

Human GC cell line SGC-7901, which was initially obtained from the cell bank of Chinese Academy of Sciences (CAS), was provided by the hospital's Laboratory Research Centre. SGC-7901 was cultured in RPMI-1640 medium (GIBCO) supplemented with $10 \%$ heat-inactivated foetal bovine serum (Hyclone) at $37^{\circ} \mathrm{C}$ in a $5 \% \mathrm{CO}_{2}$ atmosphere.

\section{Immunofluorescence}

SGC-7901 cell in 24-well plates were fixed with $4 \%$ paraformaldehyde (20 min at room temperature), treated with $0.5 \%$ Triton $\mathrm{X}-100\left(20 \mathrm{~min}\right.$ at $\left.37^{\circ} \mathrm{C}\right)$, blocked with $1 \%$ BSA $\left(30 \mathrm{~min}\right.$ at $\left.37^{\circ} \mathrm{C}\right)$, incubated with primary antibody (overnight at $4{ }^{\circ} \mathrm{C}$ ), stained with fluorescein-conjugated secondary antibody $(1 \mathrm{~h}$ at $37^{\circ} \mathrm{C}$ ), and stained with DAPI $(5 \mathrm{~min}$ at room temperature) in that order. Images were observed using a fluorescence microscope.

\section{SiRNA transfection}

Three MBD2-siRNAs (MBD2-siRNA-1, MBD2siRNA-2, and MBD2-siRNA-3) were designed by RiboBio Company, Guangzhou, China. SGC7901 cells were transfected with MBD2-siRNA duplexes $(100 \mathrm{nM})$ or Cy3 labelled siRNA (transfection control, $100 \mathrm{nM}$ ) by using the Lipofectamine ${ }^{\mathrm{TM}} 2000$ reagent (Invitrogen), according to the manufacturer's protocols.

\section{RT-PCR}

Total RNA of SGC-7901 was extracted by using RNAiso Plus after $48 \mathrm{~h}$ of the siRNA transfection. The reverse transcription (RT) and polymerase Chain
Reaction (PCR) were performed by using "PrimeScript One Step RT-PCR Kit version 2 (Dye Plus)". The RT condition was $50^{\circ} \mathrm{C}$ for $30 \mathrm{~min}$. The RTase inactive condition was $94^{\circ} \mathrm{C}$ for $2 \mathrm{~min}$. The PCR conditions were as follows: $94^{\circ} \mathrm{C}$ for $30 \mathrm{sec}, 60^{\circ} \mathrm{C}$ for $30 \mathrm{sec}$ and $72^{\circ} \mathrm{C}$ for $20 \mathrm{sec}$ for 35 cycles (MBD2) or 30 cycles $(\beta$-actin). After agarose gel electrophoresis, expression of MBD2 was evaluated by the relative yield of the PCR products of the target sequence to that of the $\beta$-actin gene. The semi-quantitative formula is INT mm2 (MBD2)/INT mm2 ( $\beta$-actin). Materials used in this test were obtained from Takara Biotechnology, Dalian.

\section{Western blot analysis}

Total protein of SGC-7901 was extracted after $72 \mathrm{~h}$ of the siRNA transfection. The western blot procedure was performed according to that described in the previous study ${ }^{2}$. Materials used in this test were obtained from Beyotime Company, China.

\section{Methyl thiazolyl tetrazolium (MTT) assay}

SGC-7901 was seeded into 96-well plates at $10^{4}$ cells/well. At 24, 48, 72, 96, 120, and $144 \mathrm{~h}$ after the MBD2-siRNA transfection at a final concentration of $100 \mathrm{nmol} / 1,20 \mu \mathrm{l}$ of 3-(4,5-dimethylthiazol-2-yl)-2,5diphenyltetrazolium bromide (MTT), $5 \mathrm{~g} / \mathrm{l}$ was added into a corresponding test well, and incubated for $4 \mathrm{~h}$. The supernatant was discarded and $150 \mu \mathrm{l}$ DMSO was added to each well to dissolve the precipitate. Optical density was measured at a wavelength of $570 \mathrm{~nm}$. Each test was repeated in five wells.

\section{Statistical analysis}

Standard statistical analysis was performed using the SPSS 17.0 Package. The Wilcoxon sign-rank test, $\chi^{2}$ test, Fisher's exact test, and $t$-test were used in this study. $p<0.05$ was considered to be significant.

\section{RESULTS}

\section{Expressions of MBD2 in GC tissues}

Both GC tissues and matched non-cancerous tissues expressed MBD2 proteins (Fig. 1). The expression of MBD2 was higher in GC tissues than in matched control tissues (Fig. 2).

\section{Associations between MBD2 expression and clinical parameters of GC}

There were some associations between the MBD2 expression and the clinical parameters of GC, such as the tumour size, histological grade and $H$. pylori infection of GC tissues, by using $\chi^{2}$ test and Fisher's exact test, $p<0.05$ (Table 1 ). 

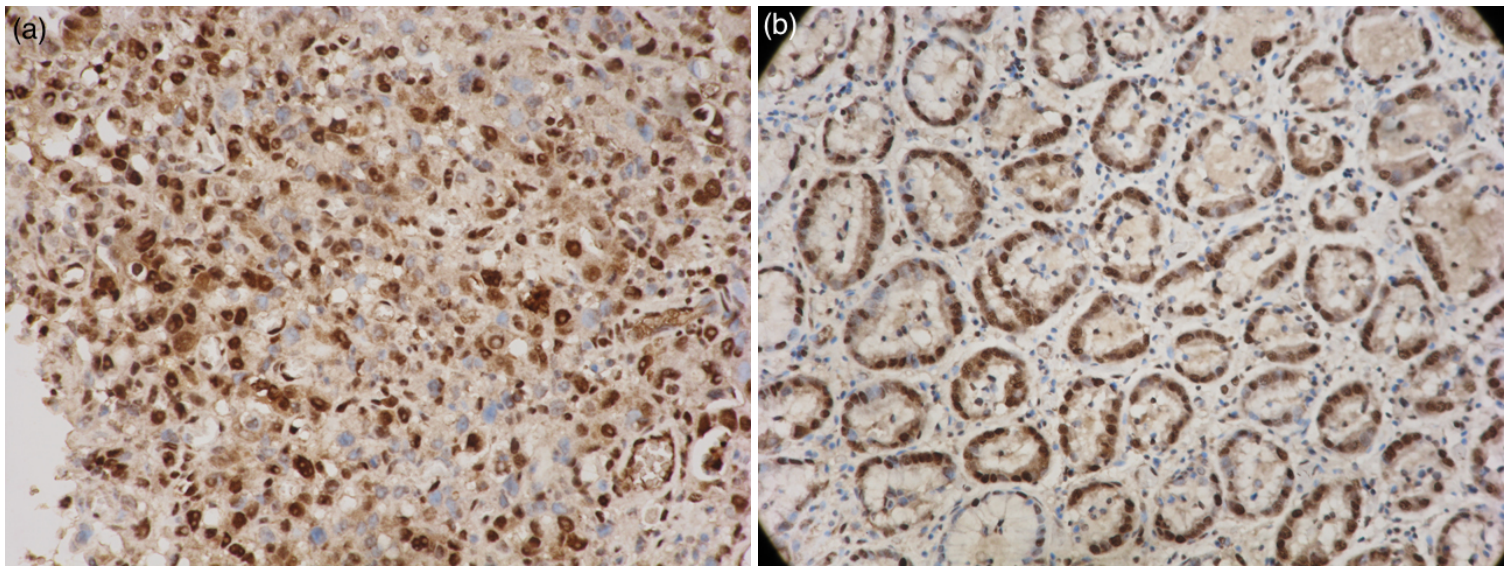

Fig. 1 Expression of MBD2 in GC (a), and in control non-cancerous tissue (b).

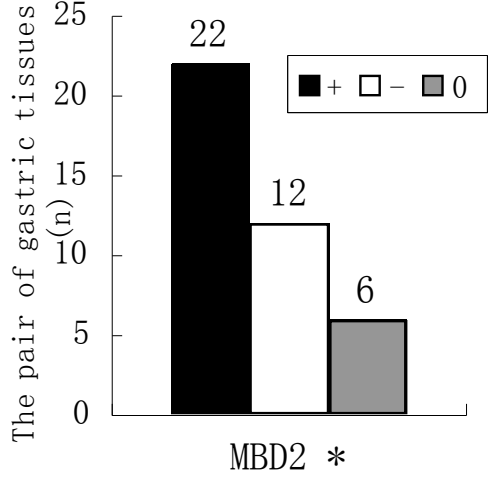

Fig. 2 Comparison of MBD2 expressions in GC and matched control tissues, immunohistochemistry. "+": MBD2 expression was higher in GC than in matched control tissue (GC's score was higher). “-”: MBD2 expression was lower in GC than in matched control tissue (GC's score was lower). "0": MBD2 expression was similar in GC and in matched control tissue (GC's score was similar to the matched control). The MBD2 expression was higher in GC tissues than in matched control tissues (“*”: $p<0.05$, Wilcoxon sign-rank test).

\section{Distribution of MBD2 in SGC-7901}

MBD2 was distributed in the nuclei of SGC-7901 (Fig. 3).

\section{Cy3 labelled siRNA transfection}

siRNA could be transfected into SGC-7901 perfectly, with the transfection efficiency nearly $100 \%$ (Fig. 4).

\section{RNA interference of MBD2 in SGC-7901}

The sequences of the MBD2 primer, $\beta$-actin primer and MBD2-siRNAs were shown in Table 2. MBD2-
Table 1 Positive MBD2 expression in differential clinical parameters of GC. $n(\%)$.

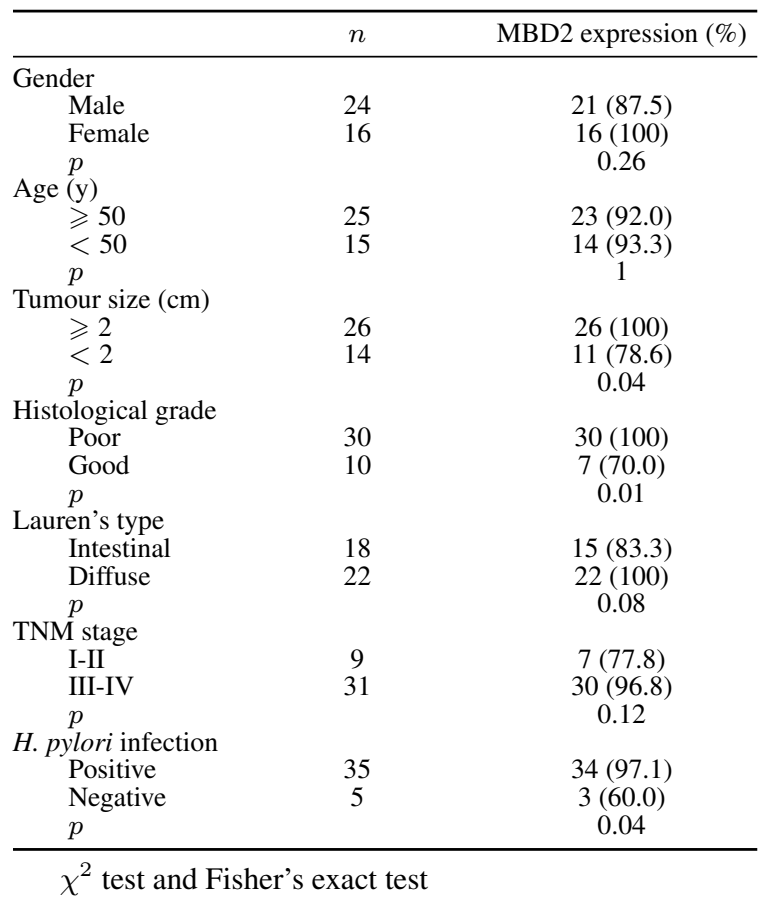

siRNA-2 suppressed MBD2 mRNA most significantly (Fig. 5, Fig. 6). MBD2-siRNA-2 could inhibit MBD2 protein in SGC-7901 (Fig. 7, Fig. 8).

\section{Methyl thiazolyl tetrazolium (MTT) assay}

MBD2-siRNA-2 could inhibit the proliferation of SGC-7901 after $96 \mathrm{~h}$ of the transfection (Table 3). However, the negative-siRNA or lipo2000 did not change the growth rate of SGC-7901 significantly in 6 days. 

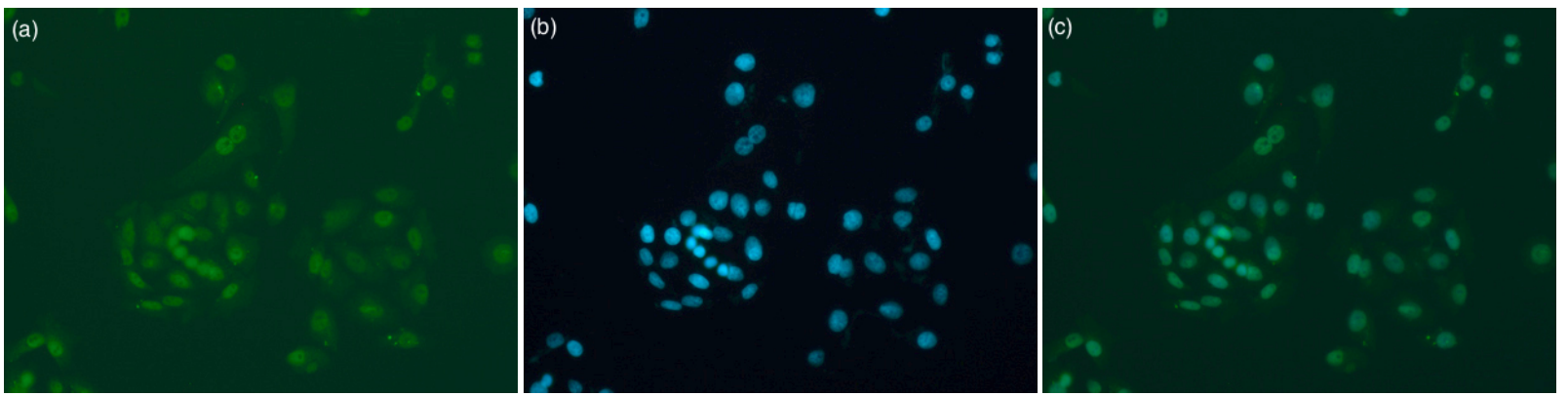

Fig. 3 Fluorescence microscopy images of the distribution of MBD2 in SGC-7901. (a) MBD2 was found in SGC-7901 nuclei; (b) DAPI was found in SGC-7901 nuclei; (c) overlay of images (a) and (b).
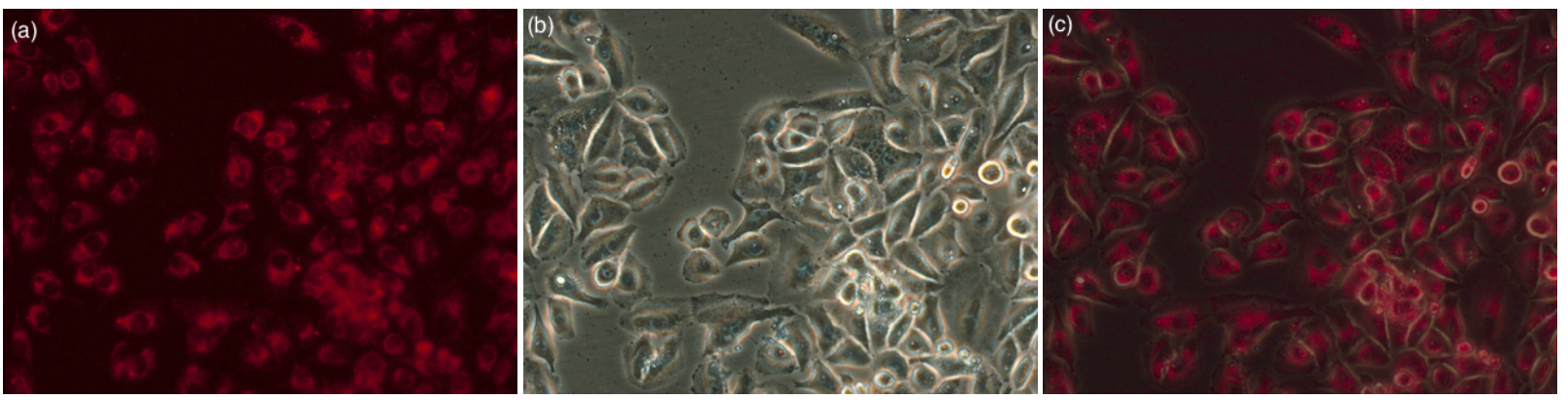

Fig. 4 The transfection of Cy3 labelled siRNA (transfection control) in SGC-7901. (a) Cy3 labelled siRNA in SGC-7901; (b) "blank" photo of SGC-7901; (c) overlay of images (a) and (b).

\section{DISCUSSION}

Epigenetics is the study of inherited genetic changes that occur without changes to the naked DNA sequence, which includes DNA methylation, histone modification, chromatin remodelling, and expression of non-coding RNAs ${ }^{3}$. DNA methylation is the most widely researched epigenetic alteration in human tumours. Human tumour cells exhibit abnormal DNA methylation patterns including the hypermethylation of $\mathrm{CpG}$ islands in tumour-suppressor genes (TSGs) and a global loss of DNA methylation in the genome ${ }^{4}$.
These changes, which are related to the inactivation of TSGs and the activation of oncogenes, may promote tumour progression ${ }^{5}$. Up to now, abnormal expressions of DNA methyltransferase (DNMT) and MBD2 are regarded to play important roles in the aberrant DNA methylation that occurs in tumours ${ }^{6}$. DNMT proteins may promote tumour progression through the hypermethylation-mediated inactivation of TSGs in $\mathrm{CpG}$ islands ${ }^{7}$. Some studies suggested that tumours expressed DNMT proteins highly and the DNMT inhibitor could be useful for tumour treatment ${ }^{8}$. The MBD2 protein may also play a role in tumours.

Table 2 Primer sequences.

\begin{tabular}{ll}
\hline name & sequence \\
\hline actin & Forward Primer: $5^{\prime}-$ TCAAGATCATTGCTCCTCCTGAG $-3^{\prime}$ \\
& Reverse Primer: $5^{\prime}-$ ACATCTGCTGGAAGGTGGACA $-3^{\prime}$ \\
MBD2 & Forward Primer: $5^{\prime}-$ CCCTGCTGTTTGGCTTAACACATCTC $-3^{\prime}$ \\
& Reverse Primer: $5^{\prime}-$ TGCGTACTTGCTGTACTCGCTCTTC $-3^{\prime}$ \\
MBD2-siRNA-1 & $5^{\prime}-$ GAAAGAUGAUGCCUAGUAATT $-3^{\prime}$ \\
& $5^{\prime}-$ UUACUAGGCAUCAUCUUUCTT $-3^{\prime}$ \\
MBD2-siRNA-2 & $5^{\prime}-$ GUAAGAAGUUCAGAAGCAATT $-3^{\prime}$ \\
& $5^{\prime}-$ UUGCUUCUGAACUUCUUACTT $-3^{\prime}$ \\
MBD2-siRNA-3 & $5^{\prime}-$ GCGAAACGAUCCUCUCAAUTT $-3^{\prime}$ \\
& $5^{\prime}-$ AUUGAGAGGAUCGUUUCGCTT $-3^{\prime}$ \\
\hline
\end{tabular}


Table 3 Relative growth rate of SGC-7901 after the MBD2-siRNA-2 transfection, MTT assay.

\begin{tabular}{lllllll}
\hline & $24 \mathrm{~h}$ & $48 \mathrm{~h}$ & $72 \mathrm{~h}$ & $96 \mathrm{~h}$ & $120 \mathrm{~h}$ & $144 \mathrm{~h}$ \\
\hline control & 1 & 1 & 1 & 1 & 1 & 1 \\
lipo2000 & $0.993 \pm 0.078$ & $0.988 \pm 0.095$ & $0.983 \pm 0.077$ & $0.982 \pm 0.072$ & $0.983 \pm 0.069$ & $0.985 \pm 0.077$ \\
Negative-siRNA & $0.997 \pm 0.041$ & $0.987 \pm 0.091$ & $0.980 \pm 0.069$ & $0.977 \pm 0.067$ & $0.973 \pm 0.082$ & $0.972 \pm 0.072$ \\
MBD2-RNAi & $0.982 \pm 0.061$ & $0.948 \pm 0.064$ & $0.928 \pm 0.080$ & $0.895 \pm 0.081^{*}$ & $0.858 \pm 0.084^{*}$ & $0.808 \pm 0.072^{*}$ \\
\hline
\end{tabular}

${ }^{*} p<0.05$ versus control, average $\pm \mathrm{SD}, b=5, t$-test.

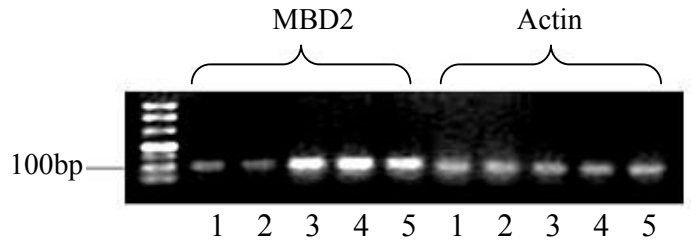

Fig. 5 Effect of MBD2-siRNAs on MBD2-mRNA inhibition in SGC-7901, RT-PCR. Lane 1: MBD2-siRNA-1; lane 2: MBD2-siRNA-2; lane 3: MBD2-siRNA-3; lane 4: negative siRNA; lane 5: negative control (nontransfected). MBD2-siRNA-2 inhibited the MBD2 mRNA most significantly. $\beta$-actin was the internal control.

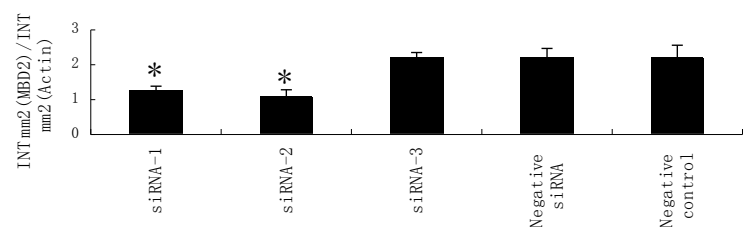

Fig. 6 The inhibition of MBD2 mRNA by siRNAs in SGC-7901, RT-PCR. MBD2-siRNA-2 inhibited the MBD2 mRNA most significantly $(* p<0.05$ versus negative control, $t$-test, mean $\pm \mathrm{SD}, n=3$ ). MBD2-siRNA-2 was chosen for subsequent test.

MBD2 protein is regarded as a mediator of biological consequences of the DNA methylaion signal. MBD2 protein selectively bind to methylated DNA at the methyl-CpG in transcription start sites regions ${ }^{9}$ and can repress the transcription from methylated gene promoters through recruit chromatin remodelling and transcriptional repressor complexes ${ }^{10}$. In addition, MBD2 is also reported as a demethylase to activate transcription ${ }^{11,12}$. For tumours, MBD2 protein may exacerbate carcinogenesis by increasing tumour size and number through repress the transcription of methylated tumour suppressors ${ }^{13}$. And the knockdown of MBD2 may suppress the proliferation of different tumours. For example, Glioblastoma multiforme expressed MBD2 significantly and the targeted

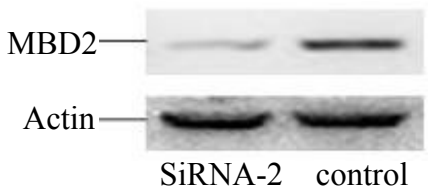

Fig. 7 The inhibition of MBD2 protein in SGC-7901, western blotting. MBD2-siRNA-2 could inhibit the MBD2 protein in SGC-7901. $\beta$-actin was the internal control.

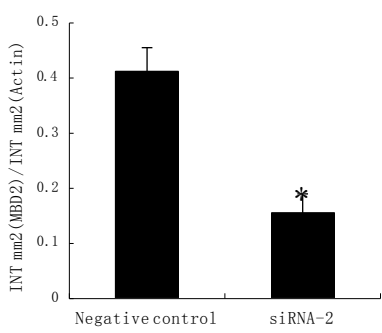

Fig. 8 The inhibition of MBD2 protein by siRNA in SGC7901, western blotting. MBD2-siRNA-2 could inhibit the MBD2 protein in SGC-7901 (* $p<0.05$ versus negative control, $t$-test, mean $\pm \mathrm{SD}, n=3$ ).

inhibition of MBD2 could suppress glioma pathobiology by reactivating tumour suppressor BAI $1{ }^{14}$. In breast cancer, the knockdown of MBD2 could inhibit cancer proliferation by activating tumour suppressor DAPK1 and KLK10 ${ }^{1}$. And the MBD2 knockdown might also inhibit the lung cancer and colorectal cancer, but didn't affect the growth of normal cells in vitro or exhibit overt toxicity in vivo ${ }^{15}$. These findings suggest the underlying values of MBD2 for tumour therapy and may play a role in gastric cancer.

In this study, we found GC expressed MBD2 protein in nuclei more significantly than matched mucosa tissues. In addition, the expression of MBD2 was associated with the clinical parameters of GC, such as tumour size, histological grade, and so on. In addition, the knockdown of MBD2 could inhibit the proliferation of GC cells even after a transient transfection of specific siRNA was performed. These 
findings are encouraging and suggest that MBD2 is required for GC progression and may have underlying value for GC diagnosis and therapy. Certainly, there caveats in our study. For example, only $40 \mathrm{GC}$ tissues and one GC cell line were analysed, stable knockout of MBD2 was not performed, no tests in vivo were included, and the exact mechanism of how MBD2 effects on GC proliferation was unknown. Further studies may solve these issues.

\section{REFERENCES}

1. Mian OY, Wang SZ, Zhu SZ, Gnanapragasam MN, Graham L, Bear HD, Ginder GD (2011) Methylbinding domain protein 2-dependent proliferation and survival of breast cancer cells. Mol Canc Res 9, 1152-62.

2. Jung Y, Park J, Kim TY, Park JH, Jong HS, Im SA, Robertson KD, Bang YJ, Kim TY (2007) Potential advantages of DNA methyltransferase 1 (DNMT1)targeted inhibition for cancer therapy. J Mol Med 85, 1137-48.

3. Esteller M (2011) Cancer epigenetics for the 21st Century: What's next? Gene Canc 2, 604-6.

4. Daniel FI, Cherubini K, Yurgel LS, de Figueiredo MA, Salum FG (2011) The role of epigenetic transcription repression and DNA methyltransferases in cancer. Cancer 117, 677-87.

5. Bender CM, Pao MM, Jones PA (1998) Inhibition of DNA methylation by 5-aza-2'-deoxycytidine suppresses the growth of human tumor cell lines. Canc Res 58, 95-101.

6. Fang JY, Cheng ZH, Chen YX, Lu R, Yang L, Zhu HY, Lu LG (2004) Expression of Dnmt1, demethylase, $\mathrm{MeCP} 2$ and methylation of tumor-related genes in human gastric cancer. World J Gastroenterol 10, 3394-8.

7. Vertino PM, Yen RW, Gao J, Baylin SB (1996) De novo methylation of $\mathrm{CpG}$ island sequences in human fibroblasts overexpression DNA (cytosine-5-)methyltransferase. Mol Cell Biol 16, 4555-65.

8. You BR, Park WH (2012) Zebularine inhibits the growth of HeLa cervical cancer cells via cell cycle arrest and caspase-dependent apoptosis. Mol Biol Rep 39, 9723-31.

9. Chatagnon A, Perriaud L, Nazaret N, Croze S, Benhattar J, Lachuer J, Dante R (2011) Preferential binding of the methyl-CpG binding domain protein 2 at methylated transcriptional start site regions. Epigenetics 6, 1295-307.

10. Berger J, Bird A (2005) Role of MBD2 in gene regulation and tumorigenesis. Biochem Soc Trans 33, 1537-40.

11. Zhu Y, Spitz MR, Zhang H, Grossman HB, Frazier ML, Wu X (2004) Methyl-CpG-binding domain 2: a protective role in bladder carcinoma. Cancer 100, 1853-8.
12. Szyf M (2010) Epigenetic therapeutics in autoimmune disease. Clin Rev Allergy Immunol 39, 62-77.

13. Sansom OJ, Berger J, Bishop SM, Hendrich B, Bird A, Clarke AR (2003) Deficiency of Mbd2 suppresses intestinal tumorigenesis. Nat Genet 34, 145-7.

14. Zhu D, Hunter SB, Vertino PM, Van Meir EG (2011) Overexpression of MBD2 in glioblastoma maintains epigenetic silencing and inhibits the antiangiogenic function of the tumor suppressor gene BAI1. Canc Res 71, 5859-70.

15. Campbell PM, Bovenzi V, Szyf M (2004) Methylated DNA-binding protein 2 antisense inhibitors suppress tumourigenesis of human cancer cell lines in vitro and in vivo. Carcinogenesis 25, 499-507. 